\title{
Simultaneous determination of multiple mRNA levels utilizing MALDI-TOF mass spectrometry and biotinylated dideoxynucleotides
}

\author{
DANIEL SCOTT DUFFIELD, ${ }^{1} \mathrm{LI} \mathrm{CAI}^{2}$ and SOBIN KIM ${ }^{2}$ \\ ${ }^{1}$ Department of Chemical and Biochemical Engineering, Rutgers University, Piscataway, New Jersey 08854, USA \\ ${ }^{2}$ Department of Biomedical Engineering, Rutgers University, Piscataway, New Jersey 08854, USA
}

\begin{abstract}
Here we report an efficient method to simultaneously measure multiple mRNA levels utilizing mass spectrometry (MS) and molecular affinity isolation. In this approach, reverse transcription products of a group of mRNAs are subjected to competitive PCR with competitors and internal standards of known concentrations, and the PCR products are differentiated and quantified by matrix-assisted laser desorption/ionization time-of-flight (MALDI-TOF) MS to determine the mRNA levels. The method provides high accuracy in quantitative MS analysis due to the facilitated purification of oligonucleotides by molecular affinity isolation. Additionally, owing to the molecular affinity isolation, only those oligonucleotides required for expression level determination are introduced into the mass spectrometer, while other irrelevant reaction components that could overlap with peaks of gene transcripts or competitors are removed prior to MS analysis. Thus the approach enhances the parallel analysis of multiple gene transcripts by MS. Utilizing the method we have simultaneously measured mRNA levels of four genes (Rho, NrI, $H$ prt, and $L h \times 2)$ in mouse retinal tissue.
\end{abstract}

Keywords: gene expression; MALDI-TOF; mass spectrometry; biotinylated ddNTPs; multiplexing; mouse retina

\section{INTRODUCTION}

Gene expression is a critical step that influences myriad cellular processes. Alterations in gene expression have been implicated in various complex diseases such as cancer, type-1 diabetes, Crohn's disease, and rheumatoid arthritis (Vogelstein and Kinzler 2002, 2004; Plenge et al. 2007; Barrett et al. 2008; Concannon et al. 2009). Furthermore, they could provide information on inter-individual differences in the susceptibility, progress, and treatment of disease (Faria et al. 2007; Selzner et al. 2008; Landers et al. 2009). Gene expression patterns are most typically determined by quantifying mRNA levels. Therefore mRNA level measurement is a frequently required experimental procedure, and the methods to analyze mRNA levels are in high demand. Here we present a highly efficient method to simultaneously monitor multiple mRNA levels utilizing mass spectrometry and molecular affinity isolation.

Reprint requests to: Sobin Kim, Department of Biomedical Engineering, Rutgers University, Piscataway, NJ 08854, USA; e-mail: sobinkim@ rci.rutgers.edu; fax: (732) 445-3753.

Article published online ahead of print. Article and publication date are at http://www.rnajournal.org/cgi/doi/10.1261/rna.1859810.
Common methods for monitoring mRNA levels include, but are not limited to, microarrays (Schena et al. 1995), serial analysis of gene expression (SAGE) (Velculescu et al. 1995), and reverse transcription quantitative PCR (RTqPCR) (Heid et al. 1996; Bartlett 2002). DNA microarrays are capable of very high throughput genome-wide analysis, on the order of tens of thousands of genes in one assay, but require larger sample amounts and are limited to analyzing relative expression levels (Schena et al. 1995; Kong et al. 2009). Thus microarrays are often used for initial screening of expression levels of a large group of genes, from which a smaller set of candidate genes is selected for further verification (Jaluria et al. 2007). Another common method, SAGE, which also offers genome-wide gene expression analysis, has a sensitivity advantage over microarrays but is time- and labor-intensive (Velculescu et al. 1995). Addressing these issues, polony multiplex analysis of gene expression (PMAGE), an adaptation of SAGE, has been reported. This method provides the benefit of combining high throughput sequencing technology with the sensitivity and comprehensiveness of SAGE (Kim et al. 2007). However, this method is not as practical for studies including a small number of genes. In such studies and for verification 
of microarray data, RT-qPCR methods have become the gold standard as they are highly sensitive, fast, and could allow quantification of absolute transcript levels (Bustin 2000). A major pitfall, however, of RT-qPCR methods is the low throughput, with most assays limited to analyzing a single gene per reaction (VanGuilder et al. 2008).

The real competitive PCR (rcPCR) approach has been demonstrated to address the throughput issue of RT-qPCR by employing mass spectrometry (Ding and Cantor 2003). In this approach, a competitor is designed to match the sequence of a portion of a gene transcript save for a single base, and is subjected to a competitive PCR reaction with the gene transcript. The PCR products are then quantified through a primer extension reaction followed by MS. The primer extension reaction is performed with a combination of certain deoxynucleotide triphosphates (dNTPs) and dideoxynucleotide triphosphates (ddNTPs) that are preselected according to the gene and competitor sequences to ensure a mass difference large enough for high resolution in MS analysis. This approach allows fast and multiplexed measurement of mRNA levels by employing matrixassisted laser desorption ionization time-of-flight mass spectrometry (MALDI-TOF MS). Together with electrospray ionization (ESI), MALDI is one of the most frequently used ionization methods for biological samples. While ESI is often employed in the analysis of peptides and proteins, MALDI has been widely used in the analysis of oligonucleotides (Gut 2004; El-Aneed et al. 2009). Furthermore, ESI produces many multiply charged ions, a tendency that may interfere with quantification (El-Aneed et al. 2009). Therefore, we chose to employ MALDI-TOF MS in the present study to quantitatively measure multiple mRNA levels in one mass spectrum addressing one major drawback of MALDI-TOF MS, the requirement of high sample purity. The issue has not been effectively dealt with previously but could become more critical in quantitative assays including the measurement of mRNA levels.

Addressing the issue of sample purification requirement for MALDI-TOF MS and aiming to achieve higher multiplexing capability than current MS-based methods, here we have developed a mRNA level monitoring method (Fig. 1) involving molecular affinity isolation and MALDI-TOF MS. The method allows simultaneous analysis of multiple genes by exploring solid phase capture-single base extension (SPC-SBE) (Kim et al. 2002, 2003). The SPC-SBE approach is a highly multiplexed method for sequence variation detection, and it involves SBE reaction with biotinylated ddNTPs (biotin-ddNTPs) to differentiate sequence variations and subsequent isolation of the biotinylated extension products by molecular affinity capture prior to the MS analysis (Kim et al. 2002, 2003). The resulting mass spectra then are free of any primers and contain only the extension products that are well-resolved in mass, allowing a higher level of multiplexing in MALDI-TOF

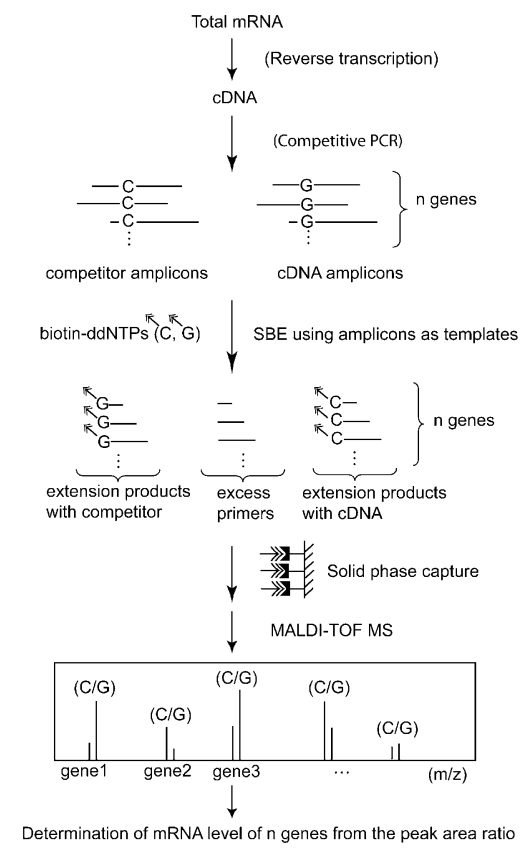

FIGURE 1. Simultaneous determination of multiple mRNA levels using mass spectrometry and biotinylated dideoxynucleotides. Gene transcripts are isolated and coamplified with competitors designed to carry a single base alteration. A library of SBE primers is extended by biotin-ddNTPs, purified using SPC, and then analyzed quantitatively using MALDI-TOF MS.

MS. Previously this method has been used to simultaneously detect 50 SNPs (single nucleotide polymorphisms), which is the highest level of multiplexing utilizing MALDITOF MS to the best of our knowledge (Misra et al. 2007). In this approach, the SPC procedure to isolate biotinylated extension products removes salts and other reaction components that can interfere with mass spectral analysis, and thus can promote accurate quantitative MALDI-TOF MS measurement. Therefore the high multiplexing capability and facilitation of quantitative MS measurement suggests SPC-SBE as an ideal approach for determination of mRNA levels.

As shown in Figure 1, the approach for mRNA level monitoring involves SPC-SBE and competitive PCR (cPCR). As in rcPCR, a gene transcript and its matching competitor (an internal standard with a single base alteration and at a known concentration) are simultaneously amplified. Then the PCR products are quantified using the SPC-SBE method, providing a reliable and quantifiable way of discerning a gene transcript from its competitor. In addition to allowing higher levels of multiplexing, SPC procedures facilitate the quantitative MALDI-TOF MS measurement by enhancing sample purification, which is critical in accurate determination of gene expression levels. Furthermore, the presented approach has the potential for automation and further increases in the level of multiplexing. 


\section{RESULTS AND DISCUSSION}

\section{Simultaneous and quantitative expression assay of four genes}

Here we demonstrated simultaneous determination of mRNA levels of four genes (Rho, Nrl, Hprt, and $L h \times 2)$ in mouse retinal tissue utilizing our approach that involves molecular affinity isolation and mass spectrometry (Fig. 1). These four genes were chosen since their expression levels were thought to vary significantly in adult mouse retina and were proper for the demonstration of the proposed method (Blackshaw et al. 2004). An 80-base pair (bp)-long region of each gene was chosen for CPCR and a competitor was designed to carry the same sequence with a single base alteration in the middle of the region (Table 1). Then we performed simultaneous CPCR with reverse transcription products of all four genes and their competitors in one reaction tube. This was followed by a multiplexed SBE reaction with all four SBE primers, SPC, and finally MALDI-TOF MS.

As shown in Figure 2, all eight products of the four SBE primers had strong mass spectral signal, and we were able to accurately determine the identity of a gene or the corresponding competitor from the mass-per-charge ratios of two extension products ( $C$ and $G$ extensions) for each SBE primer. For instance, the first two peaks at masses of $4929 \mathrm{Da}$ and $4968 \mathrm{Da}$ represent, respectively, the C (gene transcript)—and $\mathrm{G}$ (competitor)—extension products of the Lhx2 SBE primer. We chose all competitors to carry a $\mathrm{G} / \mathrm{C}$ alteration, since the $\mathrm{C}$ - and $\mathrm{G}$-extension products would have a $39-\mathrm{Da}$ mass difference (Table 2), which can be easily measured with completely resolved mass peaks as shown in Figure 2. Additional peaks that are present in Figure 2 are not gene transcripts or gene competitor peaks. These peaks appear at distinct mass-per-charge ratio $(\mathrm{m} / \mathrm{z})$ and are products of salt adduction, specifically sodium ions, to the analytes. Separate data analyses were performed, one taking into account only the analyte peaks and another taking into account both the analyte peaks and the primary salt peaks. No significant difference in quantification was observed between the two methods. Furthermore, the salt adduct peaks appear only at distinct $m / z$ very close to their analyte peaks and not where a subsequent analyte would ideally be designed to appear. Therefore, they do not limit the multiplexing capability of the presented method. Additionally, random noise peaks were much lower in both the intensity and the peak area levels than sample peaks or salt adduct peaks and thus not counted in the analysis. Measuring the area under each peak and calculating their ratio allowed us to quantify the relative concentrations of the two different extension products, which revealed the quantity of the gene transcript when compared with the known initial competitor concentration (Table 3). The initial competitor concentration was optimized as described in Materials and Methods since the accuracy in quantitative MALDI-TOF MS measurement would be best when mass spectral peak areas are comparable and the gene transcript/competitor pairs are within an order of magnitude in concentration.

As shown in Table 3, Rho was expressed the most, on an order of magnitude higher scale, while $\mathrm{Nrl}$ and $\mathrm{Hprt}$ were expressed on comparable levels, and $L h \times 2$ had the lowest concentration of gene transcripts in the sample. Assays were performed in triplicate and repeated twice. For external calibration in quantification, we used a standard curve obtained with synthetic templates that were mixed at five different ratios, as described in Materials and Methods. The data in Table 3 show a standard deviation for measured gene transcript concentrations within $11 \%$ of the mean in all four cases. These results are generally in good agreement with previous studies (Mears et al. 2001; Xi et al. 2003; Blackshaw et al. 2004; Yoshida et al. 2004).

The results shown here indicate that the SPC-SBE approach is ideal for multiplexed gene expression assays based on MALDI-TOF MS. Previously SPC-SBE has been used for highly multiplexed SNP genotyping, and up to 50 SNPs have been analyzed simultaneously (Misra et al. 2007). In this method, the use of biotinylated ddNTPs in SBE reactions involves isolation of extension products from unextended primers and other reaction components prior to MALDI-TOF MS. The unextended primers and their dimers could otherwise appear in the mass spectra and overlap with extension product peaks, limiting the level of multiplexing. The SPC-SBE approach allows us to analyze extension products in the absence of unextended primers and is highly desirable for multiplexed assays of SNPs and other sequence variations. As shown here, the high multiplexing capacity of the method can be effectively engaged to develop a gene expression analysis that could potentially characterize 50 gene transcript levels per assay.

TABLE 1. Competitor sequences

\begin{tabular}{ll}
\hline Gene & \multicolumn{1}{c}{ Competitor sequences } \\
\hline Lhx2 & 5'-CTGCACAGAGAACCGCCTGTAGTAGTCTTCTTTCCAGTAGATGCTGCCATCCTTGCTGAAGCAGGTGAGTTCCG-3' \\
$R h o$ & 5'-GCATGCCTCAGGGATGTACCTCGACCAGCCACGAGTGGGGGAGCAGCACAGGCCAACGCCATGATCCAGGTGAAGA-3' \\
$\mathrm{Nrl}$ & 5'-ATCTCTCGGGCAGCTGGACATGCTGGGCTCCTGTCTCTCCCGGGCTCCCTCAATAGTAGCCAAGAGGCCCTTCCATAG-3' $^{\prime}$ \\
Hprt & 5'-TCGAGAGGTCCTTTTCACCAGCAACCTTGCAACCTTAACCATTTTGGGGCTGTACTGCTTAACCAGGGAAAGCAA-3' $^{\prime}$ \\
\hline Sequence variation (G to C) sites are shown in bold and underlined.
\end{tabular}

Sequence variation (G to C) sites are shown in bold and underlined. 


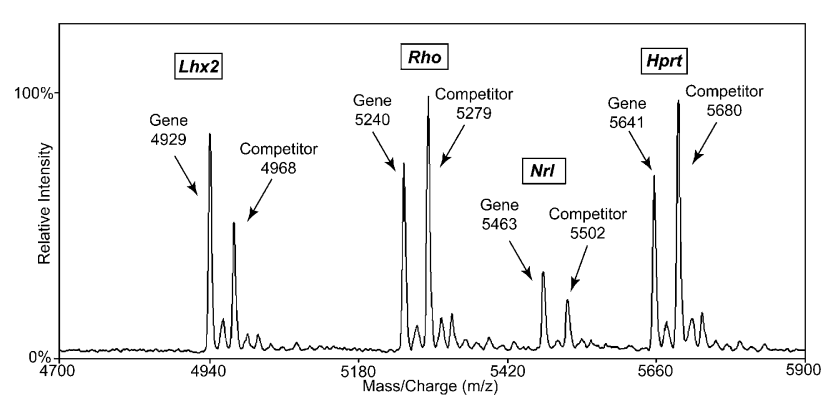

FIGURE 2. A representative mass spectrum showing multiplex analysis of expression of four genes in mouse retinal tissue. The peak area ratio of a pair of peaks together with initial competitor concentration is used to determine the expression level of one gene. G extensions represent competitors, and $\mathrm{C}$ extensions represent gene transcripts.

Additionally, the SPC-SBE approach brings unique advantages to the analysis of gene expression, which involves both qualitatively and quantitatively detecting CPCR products of gene transcript/competitor pairs that carry a single base alteration. First, the SBE reaction with biotinylated ddNTPs in SPC-SBE produces biotinylated extension products that are identical in length but have mass differences large enough to produce completely resolved peaks. In this study, G/C variation was used for all four genes, which resulted in a mass difference of $39 \mathrm{Da}$. Accuracy of quantification by peak area ratio, such as in gene expression analysis here, would be reduced if the peaks are not completely resolved, and thus the mass difference of 39 $\mathrm{Da}$ ensuring complete resolution of mass peaks was adequate for the approach. On the other hand, this mass difference of $39 \mathrm{Da}$ mitigates the peak intensity reduction that is typically shown as the mass of analyte increases. Second, the isolation of extension products using the molecular affinity between biotin and streptavidin facilitates sample purification, which results in more consistent crystallization of sample-matrix mixture, and hence more accurate and reproducible quantification by MALDI-TOF MS (Bucknall et al. 2002). Therefore owing to the high multiplexing capacity and enhanced quantitative MALDI-TOF MS, the presented method can make a robust and unique tool for simultaneous expression analysis of many genes.

\section{Verification by RT-qPCR}

To confirm the results obtained by SPCSBE and CPCR, we performed RT-qPCR for the four selected genes. Each RTqPCR reaction was performed in triplicate, and threshold cycle values were obtained for each gene as shown in Table 4. If optimal PCR efficiency is assumed, which is a reasonable assumption for amplicons designed to be $<150 \mathrm{nt}$, the difference in PCR threshold cycle numbers can be used to determine the relative difference in concentration among gene transcripts. Each difference of 1 cycle corresponds to a twofold difference in transcript level. Using this information, each gene's transcript level with respect to Hprt was calculated, and the two methods were compared (Table 4). The data obtained by RT-qPCR were consistent with the results from the SPCSBE-based method in that the four gene transcripts had a high (Rho), medium ( $N r l$ and Hprt), and low (Lhx2) expression level. As shown in Table 4, expression levels of Rho and $\mathrm{Nrl}$ determined by RT-qPCR and by the SPC-SBEbased method differed about twofold. This deviation between the two methods is caused by a combination of error introduced in the RT-qPCR and the MS quantification shown in Table 4. Up to $25 \%$ variation from the mean has been observed during the calibration curve experiments as outlined in Materials and Methods. This, along with a relatively low $R^{2}$ value associated with the curve, can account for the difference between the two presented methods. This suggests that the overall accuracy of the MS-based approach could be lower than what the error value for MS quantification shown in Table 4 would indicate, explaining the twofold difference between the two measured levels of gene expression. While the two quantification methods do not show perfect agreement, the data agree on an order-of-magnitude scale, suggesting the strong feasibility of our MS-based method for quantification of gene transcripts. Furthermore, the accuracy of the MS-based method can be increased by implementing automated systems to more accurately handle small volumes of reagents and sample solutions; thus increasing repeatability.

\section{Conclusions}

We were able to simultaneously quantify four gene transcripts in mouse retinal tissue utilizing SPC-SBE, a MALDI-TOF MS-based genotyping method that uses molecular affinity isolation. The gene expression assay shown here had accuracy comparable to RT-qPCR, and the results were in line with previously published reports. Our method involves the SPC purification and affords several advantages. First, it allows for analysis of more genes per assay as removal of unreacted primers effectively provides more spectrum space for analysis of extension products, and
TABLE 2. SBE primers for four selected gene transcripts

\begin{tabular}{|c|c|c|c|c|}
\hline \multirow[b]{2}{*}{ Gene } & \multirow[b]{2}{*}{ Primer sequences } & \multirow{2}{*}{$\begin{array}{l}\text { Mass } \\
(\mathrm{Da})\end{array}$} & \multicolumn{2}{|c|}{ Mass of SBE products (Da) } \\
\hline & & & Biotin-ddC & Biotin-ddG \\
\hline Lhx2 & 5'-GGCAGCATCTACTG-3' & 4264 & 4929 & 4968 \\
\hline Rho & 5'-ACTCGTTGGCTGGTC-3' & 4575 & 5240 & 5279 \\
\hline $\mathrm{Nrl}$ & 5'-ССТСТTGGСТАСТАTT-3' & 4798 & 5463 & 5502 \\
\hline Hprt & 5'-TGGTTAAGGTTGCAAG-3' & 4976 & 5641 & 5680 \\
\hline
\end{tabular}

Extension products with gene transcripts are shown in bold. 
TABLE 3. Measured peak area ratios for each gene, along with initial competitor concentration used in CPCR reaction and calculated gene transcript concentration

\begin{tabular}{lccc}
\hline Gene & G/C ratio & $\begin{array}{c}\text { Competitor } \\
\text { concentration } \\
(\mu \mathrm{M})\end{array}$ & $\begin{array}{c}\text { mRNA } \\
\text { concentration } \\
(\mu \mathrm{M})\end{array}$ \\
\hline Lhx2 & $0.78 \pm 0.27$ & $1.0 \times 10^{-10}$ & $4.31 \pm 0.47 \times 10^{-10}$ \\
Rho & $1.26 \pm 0.26$ & $1.0 \times 10^{-7}$ & $3.53 \pm 0.37 \times 10^{-7}$ \\
Nrl & $0.80 \pm 0.21$ & $1.0 \times 10^{-9}$ & $4.28 \pm 0.36 \times 10^{-9}$ \\
Hprt & $1.45 \pm 0.21$ & $1.0 \times 10^{-9}$ & $3.26 \pm 0.27 \times 10^{-9}$ \\
\hline
\end{tabular}

Gene transcript concentrations are calculated using the $\mathrm{G} / \mathrm{C}$ ratio and a standard curve.

(Table 1). SBE primers were designed to have the $3^{\prime}$-end anneal directly next to the base alteration site. SBE primer masses were selected so that the smallest mass difference between any two was $178 \mathrm{Da}$ to ensure that all predicted extension products would be easily and completely resolved on any given mass spectrum (Table 2).

\section{mRNA samples and reverse transcription}

Retinal tissue was excised from adult mice generously donated by Dr. Mark Plummer eliminates concern for mass overlaps among extension products and unextended primers or primer dimers. Here we have shown that four genes can be simultaneously measured for their transcript levels, but this method can be readily scaled up so that many more gene transcripts are evaluated in one reaction vessel. Since previous applications of this method to SNP characterization went as high as 50 SNPs per assay, the number of gene transcripts characterized per assay by our method could potentially reach 50 . Currently up to 25 genes can be simultaneously analyzed using MALDI-TOF MS (Sequenom; http://www.sequenom. com/Genetic-Analysis/Applications/QGE-Gene-Expression/ QGE -Literature). Second, the method uses biotin-ddNTPs in SBE reactions and produces peaks with mass differences small enough to mitigate reduction of signal but still large enough to achieve good resolution, which facilitates quantification by peak area ratios. Third, the superior sample purity of SPC-SBE enhances the mass spectrometric analysis mainly by removing unwanted salts from the sample to prevent salt adduction from interfering with quantification. The purification process also leads to generally higher sample concentrations and thus higher signal-to-noise ratios during MS analysis. These improvements in sample purity lead to more accurate and precise quantification. Therefore, the presented approach can be a viable method for measuring mRNA levels. Furthermore, our approach can be easily adapted to automation, making it a viable means of measuring gene transcript levels on a commercial scale.

\section{MATERIALS AND METHODS}

\section{Design of competitors and SBE primers}

To demonstrate the approach for multiplexed mRNA level detection, we chose four genes-Rho, Nrl, Hprt, and Lhx2-and for each gene, an $\sim 80$-bp transcriptional region was selected for cPCR amplification. Then for each selected region a synthetic template was designed to exactly match the selected region, save for a 1-base alteration introduced roughly in the middle of the sequence and Dr. Hedong Li (Rutgers University). After homogenization, we used a QIAGEN Oligotex Direct mRNA Micro Kit to isolate mRNA from the mouse retinal tissue. The protocol for animal tissues from the Oligotex Handbook was used. Quantification of mRNA products was achieved by measuring 260/280-nm absorbance levels.

We carried out reverse transcription reactions in two steps using an Ambion RETROscript reverse transcription kit. The first step was the heat denaturation of the RNA. RNA $(1.2 \mu \mathrm{g})$ was added to $2 \mu \mathrm{L}$ of random decamer primers with water making the difference to a total volume of $12 \mu \mathrm{L}$. The mixture was then heated for $3 \mathrm{~min}$ at $78^{\circ} \mathrm{C}$ and removed to ice. The second step was the reverse transcription step. Added to the reaction mixture were the following: $2 \mu \mathrm{L}$ of $10 \times \mathrm{RT}$ buffer, $4 \mu \mathrm{L}$ of $2.5 \mathrm{mM}$ dNTP mixture, $1 \mu \mathrm{L}$ of RNase inhibitor, and $1 \mu \mathrm{L}$ of MMLV-RT. This final reaction mixture was then incubated at $44^{\circ} \mathrm{C}$ for $70 \mathrm{~min}$, and then heated to $92^{\circ} \mathrm{C}$ for $10 \mathrm{~min}$ to inactivate the reverse transcriptase.

\section{Competitive PCR (CPCR)}

Reaction mixtures for $\mathrm{CPCR}$ contained the following: $5 \mu \mathrm{L}$ of $10 \times$ PCR buffer, $3 \mu \mathrm{L}$ of $2.5 \mathrm{mM}$ dNTPs, and 3 units of AmpliTaq GOLD Taq polymerase, all from Applied Biosystems; 10.5 pmol each of eight PCR primers, one forward and one reverse for each of the four genes analyzed; $3 \mu \mathrm{L}$ of cDNA from the reverse transcription step above; and $5 \mu \mathrm{L}$ of each of the following synthetic DNA competitor templates, one for each gene: $\mathrm{Nrl}, \mathrm{Hprt}$ (both at $\left.10^{-8} \mu \mathrm{M}\right)$, Rho $\left(10^{-6} \mu \mathrm{M}\right)$, and $\operatorname{Lh} \times 2\left(10^{-9} \mu \mathrm{M}\right)$. Nuclease-free water was added to bring the final reaction volume to $50 \mu \mathrm{L}$.

The reaction mixtures were then subjected to the following thermal cycle in an MJ Research PTC-200 thermal cycler: an
TABLE 4. Threshold cycle values for RT-qPCR validation study

\begin{tabular}{lccc}
\hline & \multirow{2}{*}{$\begin{array}{c}\text { RT-qPCR } \\
\text { Gene }\end{array}$} & \multicolumn{2}{c}{ Fold difference from Hprt } \\
\cline { 3 - 4 } & threshold cycle & RT-qPCR & SPC-SBE-based method \\
\hline Lhx2 & $30.26 \pm 0.28$ & $0.14 \pm 0.02$ & $0.13 \pm 0.01$ \\
Rho & $19.74 \pm 0.15$ & $198 \pm 20$ & $108 \pm 12$ \\
Nrl & $28.14 \pm 0.55$ & $0.59 \pm 0.26$ & $1.3 \pm 0.11$ \\
Hprt & $27.37 \pm 0.41$ & 1 & 1 \\
\hline
\end{tabular}

Expression level of each gene determined by RT-qPCR and the presented method is shown relative to Hprt. 
activation stage of $94^{\circ} \mathrm{C}$ for $3 \mathrm{~min}$; an amplification stage of $94^{\circ} \mathrm{C}$ for $30 \mathrm{sec}, 58^{\circ} \mathrm{C}$ for $30 \mathrm{sec}$, and $72^{\circ} \mathrm{C}$ for $30 \mathrm{sec}$ for $50 \mathrm{cycles}$; and a final extension stage of $72^{\circ} \mathrm{C}$ for $5 \mathrm{~min}$.

PCR reactions were then treated with 4 units each of Shrimp Alkaline Phosphatase and Exonuclease I (USB Corporation), and allowed to incubate at $37^{\circ} \mathrm{C}$ for $90 \mathrm{~min}$. The enzymes were then inactivated at $97^{\circ} \mathrm{C}$ for $15 \mathrm{~min}$.

\section{Single-base extension (SBE)}

SBE reactions were carried out in a $20-\mu \mathrm{L}$ volume. Thirteen microliters of products from the competitive PCR step was mixed with 50 pmol each of biotin-11-ddCTP and biotin-11-ddGTP from Perkin Elmer Life and Analytical Sciences. Added to this also was 2 units of Thermo Sequenase DNA Polymerase; $1 \mu \mathrm{L}$ of Thermo Sequenase reaction buffer; 5 pmol of SBE primers for each of Rho, Nrl, Hprt; and 10 pmol of SBE primer for Lhx2. Water was added to total the reaction volume at $20 \mu \mathrm{L}$. Reaction mixtures were then subjected to the following thermal cycle: $94^{\circ} \mathrm{C}$ for $2 \mathrm{~min}$, then $50 \mathrm{cycles}$ of $50^{\circ} \mathrm{C}$ for $30 \mathrm{sec}$ and $94^{\circ} \mathrm{C}$ for $20 \mathrm{sec}$.

\section{Solid phase capture (SPC)}

Extended SBE primers were separated from unextended ones using streptavidin-coated magnetic beads from Seradyn in the following manner: $15 \mu \mathrm{L}$ of bead solution was prewashed twice with $20 \mu \mathrm{L}$ of binding/washing buffer ( $1 \mathrm{M}$ ammonium chloride, $2 \times$ Tris-EDTA) and resuspended in $20 \mu \mathrm{L}$ of binding/washing buffer. SBE products were then mixed with the bead solution and allowed to incubate for $30 \mathrm{~min}$ at room temperature under constant but mild vortex mixing. The bead solution was then washed twice with $50 \mu \mathrm{L}$ of $1 \times$ Tris-EDTA, twice with $50 \mu \mathrm{L}$ of $0.1 \mathrm{M}$ Tri-ethylamine acetate (TEAA), and finally twice with $50 \mu \mathrm{L}$ of deionized water. The remaining solution was then suspended in $10 \mu \mathrm{L}$ of deionized water and heated from room temperature to $75^{\circ} \mathrm{C}$ at a rate of $0.5^{\circ} \mathrm{C} / \mathrm{sec}$ in order to release the bound DNA from the streptavidin-coated beads. The liquid was separated from the beads for analysis.

\section{MALDI-TOF MS analysis and calibration for quantification}

Mass spectrometric analysis was carried out on a Voyager DE-Pro MALDI-TOF MS instrument (Applied Biosystems) in linear positive mode. The matrix consisted of $18.2 \mathrm{mg}$ of 3-hydroxypicolinic acid and $3.5 \mathrm{mg}$ of ammonium citrate dissolved in $400 \mu \mathrm{L}$ of $50 \%$ acetonitrile solution (Fluka). The MALDI-TOF parameters used for analysis were $25 \mathrm{kV}$ accelerating voltage, 94\% grid voltage, $0.07 \%$ guide wire voltage, delay time of $350 \mathrm{nsec}$, and a laser intensity of 2430 . For each spectrum, 75 laser shots were taken, and for each sample, 10 spectra were accumulated.

For external calibration, we established a standard curve using two synthetic templates mimicking a gene transcript and a competitor. These synthetic DNA templates identical in sequence save for one $\mathrm{G} / \mathrm{C}$ alteration site were mixed at the following ratios: 10:1, 2:1, 1:1, 1:2, and 1:10. These mixtures were amplified and used as templates in the SBE reaction. The extension products were then purified using the solid phase capture protocol and analyzed using MALDI-TOF MS. Peak area ratios for competing extension products were plotted to the corresponding template ratios to establish a standard curve (Fig. 3). As shown in the

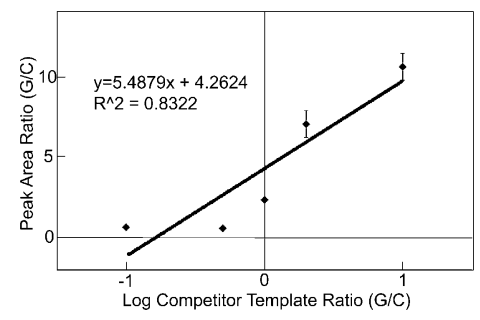

FIGURE 3. Calibration curve used to calculate gene transcript concentrations given mass spectral peak area ratios. The error for each data point ranges between $10 \%$ and $25 \%$ of the peak area ratio. Each data point is an accumulation of four different mass spectra. A linear fit on a semi-log plot was chosen to give the best available fit to the data.

standard curve, the G/C template ratios and the resulting G/C extension product ratios do not have linear proportionality. This nonlinearity is partially due to the difference in ionization efficiencies during MS analysis between $\mathrm{G}$ and $\mathrm{C}$ extension products.

To ensure high accuracy in quantification by mass spectrometry, we determined the optimal competitor concentration that closely approximated the level of each gene transcript to produce a peak area ratio within the range of the standard curve. Various concentrations of a competitor ranging over 4 orders of magnitude (0.01-10.0 amol, equivalent to $0.2-20 \mathrm{fM}$ ) were tested for individual genes. Competitor concentrations were adjusted so measured peak area ratios ( $\mathrm{G}$ to $\mathrm{C}$ ) would fall between 0.67 and 12 .

\section{Real-time quantitative PCR (RT-qPCR)}

RT-qPCR was carried out in $20-\mu \mathrm{L}$ capillaries in a Roche LightCycler using a QIAGEN QuantiTect SYBR Green PCR kit. Reaction volumes contained $5 \mu \mathrm{L}$ of SYBR Green master mix, 5 pmol each of both forward and reverse PCR primers, $1 \mu \mathrm{L}$ of cDNA from the reverse transcription step above, and water added to make a final reaction volume of $10 \mu \mathrm{L}$. Reactions were subjected to the following thermal cycle: An activation stage of $95^{\circ} \mathrm{C}$ for $15 \mathrm{~min}$; an amplification stage of $94^{\circ} \mathrm{C}$ for $30 \mathrm{sec}, 63^{\circ} \mathrm{C}$ for $30 \mathrm{sec}$, and $72^{\circ} \mathrm{C}$ for $30 \mathrm{sec}$ for 45 cycles; and a melting curve analysis stage raising the temperature from $50^{\circ} \mathrm{C}$ to $99^{\circ} \mathrm{C}$ at a rate of $0.1^{\circ} \mathrm{C} / \mathrm{sec}$.

\section{ACKNOWLEDGMENTS}

We thank Dr. Charles Roth and Dr. Salaheldin Hamed (Rutgers University) for their aid in RT-qPCR and for use of their equipment. This study was funded by grants from the NIH R03CA125785 to S.K. and NIH R21EY018738 to L.C.

Received September 11, 2009; accepted February 18, 2010.

\section{REFERENCES}

Barrett JC, Hansoul S, Nicolae DL, Cho JH, Duerr RH, Rioux JD, Brant SR, Silverberg MS, Taylor KD, Barmada MM, et al. 2008. Genome-wide association defines more than 30 distinct susceptibility loci for Crohn's disease. Nat Genet 40: 955-962.

Bartlett JMS. 2002. Approaches to the analysis of gene expression using mRNA. Mol Biotechnol 21: 149-160. 
Blackshaw S, Harpavat S, Trimarchi J, Cai L, Huang H, Kuo WP, Weber G, Lee K, Fraioli RE, Cho SH, et al. 2004. Genomic analysis of mouse retinal development. PLoS Biol 2: 1411-1431.

Bucknall M, Fung KYC, Duncan MW. 2002. Practical quantitative biomedical applications of MALDI-TOF mass spectrometry. J Am Soc Mass Spectrom 13: 1015-1027.

Bustin SA. 2000. Absolute quantification of mRNA using real-time reverse transcription polymerase chain reaction assays. J Mol Endocrinol 25: 169-193.

Concannon P, Rich SS, Nepom GT. 2009. Genetics of type 1A diabetes. N Engl J Med 360: 1646-1654.

Ding C, Cantor C. 2003. A high throughput gene expression analysis technique using competitive PCR and matrix-assisted laser desorption ionization time-of-flight MS. Proc Natl Acad Sci 100: 3059-3064.

El-Aneed A, Cohen A, Banoub J. 2009. Mass spectrometry, review of the basics: Electrospray, MALDI, and commonly used analyzers. Appl Spectrosc Rev 44: 210-230.

Faria PC, Saba K, Neves AF, Cordeiro ER, Marangoni K, Freitas DG, Goulart LR. 2007. Transforming growth factor- $\beta 1$ gene polymorphisms and expression in the blood of prostate cancer patients. Cancer Invest 25: 726-732.

Gut IG. 2004. DNA analysis by MALDI-TOF mass spectrometry. Hum Mutat 23: 437-441.

Heid CA, Stevens J, Livak KJ, Williams PM. 1996. Real time quantitative PCR. Genome Res 6: 986-994.

Jaluria P, Konstantopoulos K, Betenbaugh M, Shiloach J. 2007. A perspective on microarrays: Current applications, pitfalls, and potential uses. Microb Cell Fact 6: 4. doi: 10.1186/1475-2859-6-4.

Kim S, Edwards JR, Deng L, Chung W, Ju J. 2002. Solid phase capturable dideoxynucleotides for multiplex genotyping using mass spectrometry. Nucleic Acids Res 30: e85. doi: 10.1093/nar/ gnf084.

Kim S, Ruparel HD, Gilliam TC, Ju J. 2003. Digital genotyping using molecular affinity and mass spectrometry. Nat Rev Genet 4: 10011008.

Kim JB, Porreca GJ, Song L, Greenway SC, Gorham JM, Church GM, Seidman CE, Seidman JG. 2007. Polony multiplex analysis of gene expression (PMAGE) in mouse hypertrophic cardiomyopathy. Science 316: 1481-1484.
Kong W, Zhao JJ, He L, Cheng JQ. 2009. Strategies for profiling microRNA expression. J Cell Physiol 218: 22-25.

Landers JE, Melki J, Meininger V, Glass JD, van den Berg LH, van Es MA, Sapp PC, van Vught PWJ, McKenna-Yasek DM, Blauw HM, et al. 2009. Reduced expression of the kinesinassociated protein 3 (KIFAP3) gene increases survival in sporadic amyotrophic lateral sclerosis. Proc Natl Acad Sci 106: 9004-9009.

Mears AJ, Kondo M, Swain PK, Takadam Y, Bush RA, Saunders TL, Sieving PA, Swaroop A. 2001. Nrl is required for rod photoreceptor development. Nat Genet 29: 447-452.

Misra A, Hong J-Y, Kim S. 2007. Multiplex genotyping of cytochrome P450 single nucleotide polymorphisms by use of MALDI-TOF mass spectrometry. Clin Chem 53: 933-939.

Plenge RM, Seielstad M, Padyukov L, Lee AT, Remmers EF, Ding B, Liew A, Khalili H, Chandrasekaran A, Leela RL, et al. 2007. TRAF1-C5 as a risk locus for rheumatoid arthritis-a genome wide study. N Engl J Med 357: 1199-1209.

Schena M, Shalon D, Davis RW, Brown PO. 1995. Quantitative monitoring of gene expression patterns with a complementary DNA microarray. Science 270: 467-470.

Selzner N, Chen L, Borozan I, Edwards A, Heathcote EJ, McGilvray I. 2008. Hepatic gene expression and prediction of therapy response in chronic hepatitis C patients. J Hepatol 48: 708-713.

VanGuilder HD, Vrana KE, Freeman WM. 2008. Twenty-five years of quantitative PCR for gene expression analysis. Biotechniques 44: 619-626.

Velculescu VE, Zhang L, Vogelstein B, Kinzler KW. 1995. Serial analysis of gene expression. Science 270: 484-487.

Vogelstein B, Kinzler KW. 2002. The genetic basis of human cancer. McGraw-Hill, Toronto.

Vogelstein B, Kinzler KW. 2004. Cancer genes and the pathways they control. Nat Med 10: 798-799.

Xi J, Farjo F, Yoshida S, Kern TS, Swaroop A, Andley UP. 2003. A comprehensive analysis of the expression of crystallins in mouse retina. Mol Vis 9: 410-419.

Yoshida S, Mears AJ, Friedman JS, Carter T, He S, Oh E, Jing Y, Farjo R, Fleury G, Barlow C, et al. 2004. Expression profiling of the developing and mature $\mathrm{Nrl}^{-1-}$ mouse retina: Identification of retinal disease candidates and transcriptional regulatory targets of Nrl. Hum Mol Genet 13: 1487-1503. 

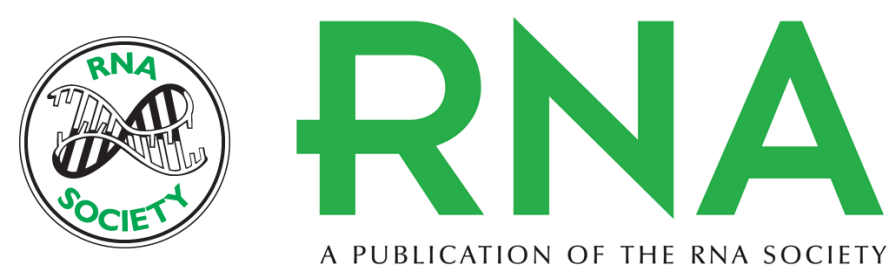

\section{Simultaneous determination of multiple mRNA levels utilizing MALDI-TOF mass spectrometry and biotinylated dideoxynucleotides}

Daniel Scott Duffield, Li Cai and Sobin Kim

RNA 2010 16: 1285-1291 originally published online April 21, 2010

Access the most recent version at doi:10.1261/rna.1859810

\section{References This article cites 27 articles, 8 of which can be accessed free at: \\ http://rnajournal.cshlp.org/content/16/6/1285.full.html\#ref-list-1}

License Email Alerting $\begin{aligned} & \text { Receive free email alerts when new articles cite this article - sign up in the box at the } \\ & \text { Service }\end{aligned}$ top right corner of the article or click here. 